\title{
A Terceirização dos Serviços de Administração Pública na Rede Hospitalar e na Educação: Um estudo na visão dos usuários
}

\author{
Wilian Oliveira Santos ${ }^{1}$; Francisco Raimundo Lopes Junior ${ }^{2}$; Alexandre Coelho Lima ${ }^{3}$; \\ Camila Coelho Lima ${ }^{4}$; Maria do Socorro Macedo Coelho Lima
}

\begin{abstract}
Resumo: Terceirização é uma expressão muito utilizada nos setores públicos e privados, tendo por significado transferir serviços. O presente trabalho apresenta questionamentos sobre a terceirização na área da saúde e da educação, com relação à eficiência e satisfação na visão de usuários e funcionários. Em se tratando de saúde, será que a mudança na gestão e a terceirização num hospital público, tem trazido a mesma eficiência ao atendimento dos clientes, na visão dos seus usuários? Ou mesmo, quando se trata da área de educação, o que muda na prestação dos serviços executados por profissionais terceirizados em relação a realização do mesmo serviço pelo profissional efetivo, na visão desse trabalhador? A pesquisa objetiva analisar as vantagens e desvantagens da terceirização de recursos humanos no campo da administração pública, na visão dos usuários desses serviços. Utiliza-se como método de abordagem do problema a pesquisa qualitativa, exploratória. Teve início com a pesquisa bibliográfica e documental, em dados secundários, e utilizando-se dados quantitativos finalizou realizando um estudo de caso com público usuário dos serviços de saúde e com profissionais de educação. Concluindo-se que a terceirização é necessária, porém trouxe mais desvantagem do que vantagem.
\end{abstract}

Palavras Chave: Terceirização. Administração pública. Rede hospitalar. Educação.

\section{The outsourcing of public administration services in the Hospital Network and Education: A study by the users view}

\begin{abstract}
Outsourcing is a term widely used in public and private sectors, with the meaning of transfer services. This paper presents questions about outsourcing in health and education with regards to efficiency and satisfaction in the view of users and employees. When it comes to health, is the change in management and outsourcing in a public hospital, has brought the same efficiency to customer service, in the view of their users? Or even when it comes to the education area, which changes in the provision of services performed by third party professionals regarding the realization of the same service for the effective professional, in the view of this worker? The research aims to analyze the advantages and disadvantages of outsourcing human resources in the field of public administration, by the users views of these services. It is used as problem of the method of approach to qualitative, exploratory research. It began with bibliographic and documentary research, secondary data, and using quantitative data finished performing a case study with user public health services and education professionals. Concluding that outsourcing is necessary, but bring more disadvantage than advantage.
\end{abstract}

Keywords: Outsourcing. Public administration. Hospital network. Education.

\footnotetext{
${ }^{1}$ Pós-Graduanda em Gestão Pública pela Universidade Federal do Vale do São Francisco-UNIVASF

${ }^{2}$ Pós-Graduanda em Gestão Pública pela Universidade Federal do Vale do São Francisco-UNIVASF

${ }^{3}$ Graduando em Medicina na Universidade Católica de Pernambuco-UNICAP.

${ }^{4}$ Médica residente em neurologia - HUPES/UFBA

${ }^{5}$ Doutoranda em Desenvolvimento Regional e Urbano; Universidade Salvador - UNIFACS. Professora Adjunta da FACAPE - Faculdade de Ciências Aplicadas e Sociais de Petrolina. Contato autor correspondente: socorrofacape@hotmail.com.
} 
Id on Line Revista Multidisciplinar e de Psicologia

Id on Line Multidisciplinary Journal and Psycology

\section{Introdução}

Terceirização é uma expressão muito utilizada atualmente, em todos os setores, tanto públicos quanto privados, tem por significado transferir serviços. Surgiu nos Estados Unidos com o advento da II Guerra mundial, quando as empresas de materiais bélicos precisaram passar para outras, algumas atividades de suporte para que fosse possível, as mesmas concentrarem suas atividades na produção de armamentos. Após o final dos conflitos, a prática da terceirização teve continuidade, tendo como fim desonerar o Estado e empresas de executarem algumas atividades que julgavam como não sendo estas imprescindíveis aos seus objetivos (GIOSA, 2008).

Drucker (2007) exalta a terceirização e as mudanças incorporadas à Administração Pública, constituindo, em princípio, como uma vantagem para o Estado, por ser essa uma prática de transferir a terceiros o papel de empregador - aquele que se responsabiliza, diretamente, pelos encargos sociais.

Atualmente, a terceirização de serviços é uma tendência mundial, principalmente nas organizações públicas, como: eletricidade, serviços gerais, vigilância, transportes, armazenamento, informática, dentre outros.

No Brasil, a terceirização surgiu paulatinamente com as primeiras empresas multinacionais. A indústria automobilística é um clássico exemplo dessa prática iniciada na década de 1980, suas fábricas ficavam apenas com as montagens dos automóveis, enquanto as peças eram adquiridas em outras empresas (QUEIROZ, 2008). Para alguns autores, essas empresas eram vistas como transnacionais porque a sua produção não possuía uma "pátria".

Buscando solucionar necessidades primordiais da Administração Pública, adentrandose no processo de contratação destes serviços de terceiros necessitados, a partir da análise do que pode ser favorável e desfavorável à otimização e descentralização, ao decidir por delegar serviços ou contratá-los, é possível afirmar que: a terceirização de serviço público encontra-se no âmbito da privatização, como forma parceira com o setor privado e conforme a Lei $\mathrm{n}^{\circ}$. 8.666/93.

Mas é preciso lembrar que a privatização não se confunde com a terceirização de mão de obra que substitui o servidor público de que trata o $\S 1^{\circ}$ do art. 18 da LRF, no que concerne à computação de despesas que dela decorrem no limite total da despesa com pessoal. 
Nesse contexto, o presente trabalho apresenta alguns questionamentos sobre a terceirização na área da saúde e da educação, tais como: em se tratando de saúde, será que a mudança na gestão e a terceirização num hospital público, tem trazido a mesma eficiência ao atendimento dos clientes, na visão dos seus usuários? Será que a relação, profissional e paciente, visto na visão da confiabilidade do usuário ao serviço ofertado, possui a mesma cumplicidade quando esta é realizada pelo profissional terceirizado? Ou mesmo, quando se trata da área de educação, o que muda na prestação dos serviços executados por profissionais terceirizados em relação a realização do mesmo serviço pelo profissional efetivo, na visão desse trabalhador?

Nesse contexto, o presente estudo tem como objetivo, analisar as vantagens e as desvantagens da terceirização de recursos humanos no campo da administração pública, na visão dos usuários desses serviços e de profissionais. Para tal, se faz necessário conhecer as horas efetivas de trabalho dos terceirizados do serviço público; analisar a maneira como é feito o atendimento ao público pelos terceirizados na visão dos usuários; e identificar os serviços que atualmente já estão sendo terceirizados na administração de um hospital público e numa escola pública municipal.

Utiliza-se como método de abordagem do problema a pesquisa qualitativa, exploratória. Inicialmente realiza-se uma pesquisa bibliográfica e documental, em dados secundários, e utilizando-se dados quantitativos finaliza realizando um estudo de caso, através da aplicação de um questionário estruturado ao público usuário dos serviços de saúde e profissionais da educação.

Enfim, esse estudo procurou conhecer, na visão da clientela da saúde, se os servidores terceirizados têm a mesma eficiência nos serviços que os efetivos, e na educação o âmbito de satisfação expressado pelos profissionais terceirizados e considerar a ocorrência de alguns aspectos apontados como negativos, pela literatura, no advento do processo de terceirização, entre eles: a redução salarial, a rotatividade de mão de obra, as piores condições no ambiente de trabalho, a incerteza na subordinação. Esses pontos, acima citados, servem apenas como subsidio, a título de exemplificação, à compreenção do embasamento do tema. Os principais doutrinadores que serão utilizados nesta pesquisa são: Artur (2007),Giosa (2008), Miraglia (2008) e Cassar (2014) que trataram com maior ênfase o tema terceirização. 
A pesquisa mostra-se relevante, no momento em que esclarece que "o serviço terceirizado é a atividade e não a empresa ou o trabalhador. A empresa terceira contrata o trabalhador, que não é terceirizado, mas faz parte do processo de terceirização" (DIEESE, 2003, p. 06). Negando-se, assim, o aspecto contraditório que existe na relação capital/trabalho, como se a terceirização pudesse superar os conflitos históricos entre essas esferas.

\section{Terceirização e Administração Pública}

Desde o Decreto-Lei 200/67, no seu Art. 10, § $7^{\circ}$, da Constituição Federal de 1988, impondo que haja maior eficiência na prestação dos serviços públicos, com a descentralização, o que acarreta uma maior demanda por serviços terceirizados, contratos com empresas privadas que possam dar suporte à Administração Pública que essa, a cada dia, busca desobrigar-se de atividades executivas, buscando recorrer, sempre que possível, à contratação de empresas privadas que possam assumir os encargos de execução de atividades.

Nesse ponto, é importante conceituar terceirização ou locação de serviços, na Administração Pública. Terceirização, atualmente, disciplinada pela Lei de Licitações e Contratos da Administração Pública, maneira pela qual o Estado busca parceria com o setor privado para a realização de suas atividades. Por meio dela, atividades de apoio ou meramente instrumentais à prestação do serviço público são repassadas para empresas privadas especializadas, a fim de que o ente público possa melhor desempenhar suas competências institucionais.

O serviço objeto de terceirização é uma tarefa prestada pelo particular imediatamente à Administração para satisfação dos interesses dessa em apoio ao exercício de suas atribuições. Outrossim relação à remuneração, na terceirização, é inteiramente paga pelo Poder Público ou pelo gestor operacional.

Cumpre-se observar ainda, que a eficiência da atividade terceirizada não é mensurada exclusivamente pela redução de custos, mas, também, por tratar-se de interesse público, onde não deve existir o intuito de lucro. 
O fato é que existem custos sociais inerentes à atuação do Estado, que não podem deixar de ser atendidos e, por isso, a análise da melhor forma de atender o interesse social deve ser feita com muita cautela. Dessa forma, é possível questionar até que ponto haverá melhoria no desenvolvimento das atividades de atendimento ao público numa Administração Pública terceirizada? Ou mesmo, qual a responsabilidade do Poder Público e da empresa contratada frente aos funcionários?

Referente as indagações acima, o atual Ministro do Trabalho - Ronaldo Nogueira, em entrevista ao Jornal do Comercio (2016), afirmou que "não há uma lei em vigor que regulamente a terceirização de atividades, existe apenas jurisprudência do Tribunal Superior do Trabalho, que impede a terceirização de atividades-fim", como exemplo, pode-se citar que numa fábrica de automóveis, um metalúrgico tem atividade-fim, e um analista de sistema, atividade-meio, aquele não deve ser terceirizado, enquanto esse, sim.

A terceirização no Estado brasileiro pode se dá por meio de: concessão; permissão, parcerias e alocação de mão-de-obra e subcontratação (DIEESE, 2006). Trata-se de uma prática com grandes possibilidades e que vem despertando algumas preocupações.

Ainda segundo dados do Ministro do Trabalho, Ronaldo Nogueira (2016), o governo enviará projetos ao Congresso para regulamentar a terceirização no país, definitivamente.

Em relação à Constituição Federal/88, em seu inciso XXI do art. 37, há o fundamento para a contratação de serviços, ao incluí-los, expressamente, entre os contratos dependentes de licitação. "É evidente que o intuito do legislador não foi o de inovar - pois tais contratos sempre foram celebrados -, mas o de tornar expresso que a licitação é obrigatória, inclusive para as entidades da Administração indireta" (PIETRO, 2005, p. 236).

Observa-se a existência de vários projetos no Congresso, tendo como objeto final a possibilidade da terceirização, e que, segundo o Ministro do Trabalho "não será liberada a terceirização de todas as atividades, mas somente de alguns serviços especializados”. Segundo esse, será necessário observar-se a cadeia econômica e, a partir dessa, quais serviços devem ser especializados e ser objeto de contrato. Compreendendo-se que, nesse caso, não se priorizará o que é atividade-fim ou atividade-meio. Nesse sentido, há que se aguardar a tão sonhada Reforma trabalhista. 
Id on Line Revista Multidisciplinar e de Psicologia

Id on Line Multidisciplinary Journal and Psycology

\section{A Prática da Terceirização no Âmbito da Administração Pública}

A terceirização de serviços, no âmbito da Administração Pública, foi regulamentada a partir da década de 1960, com o surgimento do Decreto-Lei $\mathrm{n}^{\circ} 200$, de 25 de fevereiro de 1967, (BRASIL, 2012) que dispõe sobre a organização da Administração Federal e estabeleceu diretrizes para a reforma administrativa.

Segundo Maria Sylvia Zanella Di Pietro, (2011) mesmo que não se tenha utilizado do termo terceirização propriamente dito, o referido decreto-lei autorizou a prática desta no setor público, prevendo a possibilidade de a Administração desobrigar-se da execução de tarefas executivas mediante à execução indireta.

Conforme assevera Miraglia (2008, p. 173) a permissão para a contratação de empresa terceira para execução de serviços, que não correspondam atividade-fim da Administração Pública, deu-se baseado na necessidade de desafogar a máquina estatal, com uma intervenção estatal restrita, além de menor onerosidade do setor público.

Posteriormente, a Lei $\mathrm{n}^{\circ}$ 5.645, de 10 de dezembro de 1970, (BRASIL, 2012) veio esclarecer, muito embora, não tenha apresentado um rol expressivo, entretanto, apresentou uma forma exemplificativa de quais espécies de atividades poderiam ser objeto de execução indireta, ou seja, de execução por empresas contratadas junto à iniciativa privada. Assim dispõe o parágrafo único do art. $3^{\circ}$ da referida lei:

Art. $3^{\circ}$, parágrafo único. As atividades relacionadas com transporte, conservação, custódia, operação de elevadores, limpeza e outras assemelhadas serão, de preferência, objeto de execução indireta, mediante contrato, de acordo com o artigo 10, $\S 7^{\circ}$, do Decreto-Lei n ${ }^{\circ} 200$, de 25 de fevereiro de 1967 (BRASIL, 2012).

Neste sentido, o Decreto $\mathrm{n}^{\mathrm{o}}$ 2.271, de 7 de julho de 1997, (BRASIL, 2012), surgiu tratando especificamente a respeito da contratação de serviços pela Administração Pública Federal direta, autárquica e fundacional. Nele enfatiza-se, novamente, que somente são passíveis de terceirizar as atividades-meio no âmbito da pessoa jurídica, tais como, conservação, limpeza, telecomunicações, ou seja, nenhuma atividade que tenha abrangência nos planos de cargos e carreiras dos órgãos ou entidades. Para Di Pietro: 


\begin{abstract}
No âmbito da Administração Pública Direta e Indireta a terceirização, como contrato de fornecimento de mão de obra [...] não tem guarida, nem mesmo com base na Lei $\mathrm{n}^{\mathrm{o}}$ 6.019, que disciplina o trabalho temporário, porque a Constituição, no art. 37, inciso II, exige que a investidura em cargos, empregos ou funções se dê por concurso público. A única hipótese em que se poderia enquadrar a contratação temporária, sem concurso, seria aquela prevista no art. 37, inciso IX, da Constituição, que prevê a contratação por tempo determinado para atender a necessidade temporária de excepcional interesse público. Mas esse dispositivo não é auto-aplicável. Ele só pode ser aplicado quando disciplinado em lei de cada ente governamental, essa lei é que dirá como se fazer a contratação e as hipóteses em que ela será possível.( DI PIETRO, 2011, p.219).
\end{abstract}

Para Cassar (2011, p. 536-537), a contratação de terceiros pela Administração Pública através de concessão e permissão é uma forma de terceirização amparada na Lei $\mathrm{n}^{\circ} 8$. 987/95, (BRASIL, 2012) que regulamenta o art. 175 da Constituição Federal.

Dessa forma, concessão de serviços públicos é o instituto por meio do qual o Estado, após o devido processo licitatório, atribui o exercício de um serviço público a terceiro, que aceita prestá-lo em nome próprio, por sua conta e risco, remunerando-se pela própria exploração do serviço, em geral e basicamente mediante tarifas cobradas diretamente dos usuários do serviço. (DI PIETRO, 2011)

\title{
Direitos Fundamentais do Trabalhador e Princípio da Proteção
}

À Administração Pública lhe é imputada a responsabilidade pelo pagamento de verbas trabalhistas inadimplidas pela empresa prestadora de serviços tendo, desse modo, como fundamento primeiro e, maior que legitima e valida todos os demais: os direitos fundamentais do trabalhador e o princípio da proteção.

O valor social do trabalho e a dignidade da pessoa humana são fundamentos constitucionais da República Federativa do Brasil, conforme previsto no art. $3^{\circ}$, III e IV, da Constituição Federal.

Segundo Luiz de Pinho Pedreira Machado (1999) citado por Sussekind (2010, p. 116) o princípio da proteção do trabalhador é aquele em virtude do qual "o direito do trabalho, reconhecendo a desigualdade de fato entre os sujeitos da relação jurídica de trabalho, promove a atenuação da inferioridade hierárquica e intelectual dos trabalhadores". 
Em relação à terceirização de serviços, a observância do princípio da proteção do trabalhador tem especial razão de ser, em virtude dos potenciais prejuízos que a sua prática pode acarretar ao empregado. Um deles é a redução do ordenado do trabalhador terceirizado. (MIRAGLIA,2008,p.110).

Em tese, as empresas repassam à outras a realização de alguns serviços acessórios para poderem voltar-se com mais dedicação à realização da atividade-fím do seu empreendimento e com isso melhorar a eficiência produtiva e a qualidade dos seus produtos, porém é possível que na prática, algumas empresas utilizem a terceirização com o propósito de reduzirem seus custos de produção.

Tendo esse objetivo, as tomadoras buscarão no mercado empresas que prestem serviços por preços menores, e as prestadoras, consequentemente, em função da competitividade, ofertarão seus serviços por preços cada vez mais reduzidos. Para suportar essa redução de preço sem abrir mão do seu lucro, as prestadoras acabam diminuindo a remuneração dos seus empregados de modo que esses acabem por pagar a conta da terceirização. (MIRAGLIA, 2008, 144-145).

Ademais, continua Miraglia (2008, p. 129) não exige isonomia de tratamento entre os trabalhadores terceirizados e aqueles pertencentes aos quadros da empresa terceirizada. Assim, a título exemplificativo, o trabalhador terceirizado poderá ter que cumprir carga horária de oito horas dentro do ambiente da tomadora, se assim for acordada com a sua empregadora.

O trabalhador inserido no contexto da terceirização necessita ser protegido de maneira eficaz. O não pagamento do ordenado afeta a dignidade do trabalhador, pois, via de regra, ele tem apenas na remuneração de seu labor os recursos necessários para assegurar a sua subsistência.

A regra prevista no artigo 461 da CLT, compreendendo-se, então que a contratação deverá fundamentar-se a uma equiparação salarial, utilizando analogicamente da Lei do Trabalho Temporário, Lei 6.019/74, especificadamente o seu artigo 12, alínea "a" que prevê que:

Art. 12 - Ficam assegurados ao trabalhador temporário: a) remuneração equivalente à percebida pelos empregados de mesma categoria da empresa tomadora ou clientes, calculados à base horária, garantida, em qualquer hipótese, a percepção do salário mínimo regional (BRASIL, 1974). 
Insta salientar que provavelmente, o problema da terceirização pode estar na ausência de isonomia e salário equivalente no momento em que ocorre a contratação do empregado, quando não respeitado o que ficou estabelecido na CLT ou interpretado de forma dúbia.

\section{Metodologia}

Nessa pesquisa usou-se como método de abordagem a pesquisa qualitativa de cunho exploratório utilizando dados quantitativos para analisar o resultado dos serviços terceirizados considerando suas vantagens e dificuldades. Segundo Andrade (2001, p. 121), "pesquisa é o conjunto de procedimentos sistemáticos baseados no raciocínio lógico, que tem por objetivo encontrar soluções para problemas propostos, mediante a utilização de métodos científicos.”.

Inicialmente realiza-se uma pesquisa bibliográfica, com dados secundários, apresentando os conceitos definidos pela doutrina trabalhista. Define o que se considera como prática da terceirização no âmbito da administração pública, e discute a atual necessidade de regulamentação, uma vez que a mesma encontra-se em tramitação no Congresso Nacional.

De acordo com Lakatos e Marconi (2006), “a pesquisa bibliográfica coloca o pesquisador em contato direto com tudo que já foi escrito sobre determinado assunto, permitindo que o pesquisador não apenas defina ou resolva problemas existentes, mas também explore novas áreas".

O estudo de caso: para a coleta de dados utilizou-se como ferramenta a aplicação de um questionário, contendo 06 perguntas, para os seguintes públicos: 40 (quarenta) usuários do setor público do serviço de saúde, 20 (vinte) masculino e 20 (vinte) femininos e, 39 (trinta e nove) trabalhadores efetivos ou temporários de uma escola-creche municipal sendo 8 do gênero masculino e 31 do gênero feminino distribuídos nas seguintes funções: 04 (quatro) vigilantes terceirizados; 16 (dezesseis) serviços gerais terceirizados e 02 (dois) serviços gerais efetivos; 12 (doze) professores-cuidadores terceirizados e 7 (sete) professores-cuidadores efetivos. 
Os questionários aos usuários da saúde foram feitos nas imediações do hospital, a partir de Termo de Consentimento Livre e Esclarecido, autorizando a utilização de suas respostas para fins de pesquisa acadêmica, que concordaram em participar da pesquisa, desde que fossem adotados codinomes, sendo escolhidos, pelas pesquisadoras, nomes de flores, no sentido de salvaguardar o sigilo absoluto. Os questionários aos trabalhadores da educação foram feitos numa escola pública municipal, com o consentimento da gestora. As questões elaboradas foram respondidas diretamente às pesquisadoras, para, em seguida, serem analisadas. A pesquisa ocorreu no mês de maio, no período da manhã e tarde, tendo início dia 05/06 e concluído no dia 20 do mesmo mês.

Todos representam um quantitativo de 79 (setenta e nove) pesquisados acerca do tema terceirização e nesse estudo serão aqui indicados por nomes simbólicos para resguardar suas identidades.

\section{Análise e Discussão dos dados}

A pesquisa cumpre tratar acerca das normas que asseguram proteção ao trabalhador no que se refere ao meio ambiente laboral, e posteriormente, apontar as condições de trabalho em que laboram os trabalhadores terceirizados.

É importante informar que $30 \%$, dos trabalhadores convidados, não quiseram participar da pesquisa ou dar muitas informações.

Com relação ao setor de saúde, inicialmente foi perguntado se a pessoa já tinha vindo antes ao hospital para tratamento ou acompanhando alguém, caso afirmativo, se ela tinham conhecimento do significado da terceirização de serviços. Todas as entrevistas só iniciaram após estas afirmativas.

Quando consultados se achavam que atualmente a unidade ofertava maiores serviços $48 \%$ falaram que sim e 52\% que não percebiam. Argumentaram que "continuavam precisando de serviços e não encontravam o profissional", outros que "atendimento emergencial, nem sempre tinha vaga". Que o "hospital atendia muita gente de fora e os de casa ficavam sem essa vaga" 
Quando questionados sobre a atual gerencia, anteriormente era o Governo do estado e agora terceirizado, em relação ao atendimento $68 \%$ colocaram que após a terceirização dessa unidade hospitalar, o atendimento piorou. Justificaram dizendo que "antes tambem a saúde tinha problemas", que o principal motivo para a transferência da gestão para uma Organização Social de Saúde (OSS) era a precariedade no atendimento, mas que "se antes já era um atendimento difícil, agora piorou". "Que o número de médicos era pouco e a noite principalmente, e não tinham a quem reclamar"

Quando questionados como eles qualificavam a estrutura atual do atendimento comparando com a estrutura anterior (gerida pelo governo do Estado), se tinha melhorado ou não, $40 \%$ disseram que a estrutura atual tinha contribuído para piorar o atendimento. Ao pedir uma explicação de onde estaria a causa dessa insatisfação, alguns disseram que: o Hospital "atende cerca de 500 ou mais pacientes, diariamente, o que dificulta o atendimento da população do município". Alguns afirmaram que "a atual administração dizia ofertar mais áreas de atendimento após a nova administração, porém, a maioria das especialidades ofertadas não funcionavam".

Quando consultados, na visão dos mesmos, se a terceirização gera mais desvantagens ou vantagens aos trabalhadores do hospital $25 \%$ disseram que era indiferente e $25 \%$ que não e $50 \%$ disseram que sim. Grande parte dos entrevistados que viram como desvantagem a prática atual justificou a resposta apontado que "antes da mudança o ambiente hospitalar era mais aberto ao público e todos sabiam o que acontecia, hoje, ao se chegar nas primeiras salas, o que se visualiza é organização no atendimento, no entanto, ao se entrar, de fato, nos consultórios, salas de atendimentos de urgências, berçários, dentre outros, vê-se que há muita carência de materiais e serviços".

Alguns trabalhadores consultados aceitaram falar fora da unidade hospitalar, no papel de usuário dos serviços de saúde, e deram as seguintes explicações em relação às desvantagens: "esse modelo de gestão dá margem a insatisfações, no que tange à contratação de profissionais e de serviços". A Lei de licitação não garante aos funcionários a estabilidade, antes, garantida em lei. Que "após a terceirização há mais desvantagens, pois existe uma sobrecarga de trabalho e a qualificação dos profissionais, essencial na área da saúde, ficou prejudicada por causa da alta rotatividade de trabalhadores". "Quando o profissional é concursado, pelo menos a gente sabe quem o médico e o enfermeiro do dia, e que eles vão 
Id on Line Revista Multidisciplinar e de Psicoloqia

Id on Line Multidisciplinary Journal and Psycology

continuar atendendo no município sempre porque tinham passado num concurso, e agora, não é assim".

Com relação ao comando do hospital, de uma forma geral, tivemos a seguinte resposta: "É bem verdade que um hospital é uma das empresas mais difícil de ser administrada". A complexidade de um hospital passa pelo fato de funcionar 24 horas por dia e não se ter controle sobre que paciente irá procurar o hospital. Pode atender um enfartado, de madrugada, um descolamento de placenta, à tarde, um AVC, à noite, e precisa estar preparado, com a equipe toda montada para poder atender a qualquer tipo de demanda a qualquer hora. Grande parte dos entrevistados que manifestaram insatisfação disseram que o problema era o seguinte: "todos querem chegar a uma Unidade de Saúde e ser pelo menos atendido". Que as mudanças "não melhoraram ou solucionaram situações antes existentes", e que pessoas chegam a unidade na sala de "triagem" sentindo "dores horríveis", e mesmo assim, à atendente pode dizer friamente, "seu caso não é de urgência, portanto, não será atendido". "Você retorna sem ter a quem recorrer". "Você tem que retornar para casa ou ir a outra cidade já que o gestor ou a atendente dificilmente se envolvem com a comunidade local".

Com relação à Educação as respostas foram as seguintes:

A escola possui nove salas, com cantina, refeitório e tem creche e pré-escola. Quanto ao número de funcionários efetivos e temporários, os 39 (trinta e nove) trabalhadores dessa uma escola-creche municipal 8 são do gênero masculino e 31 são do gênero feminino. $70 \%$ dos funcionários são temporários e 30\% efetivos. Estão distribuídos nas seguintes funções: 04 (quatro) vigilantes terceirizados; 16 (dezesseis) serviços gerais terceirizados e 02 (dois) serviços gerais efetivos; 12 (doze) professores-cuidadores terceirizados e 7 (sete) professorescuidadores efetivos.

Quando consultados sobre a forma de contratação $30 \%$ foram contratados através de algum processo adicional, sendo realizado por empresas/órgãos públicos ou privados, 50\% disseram que entraram por indicação política e não foram submetidos a nenhum teste adicional, e $10 \%$ optaram por outras formas de ingresso. Dentre as explicações para a falta do processo de contratação foi apontado pelos entrevistados como o principal problema da terceirização "a prática da contratação emergencial, com dispensa de licitação". 
Quando consultado sobre a diferença na realização de função $44 \%$ disseram que não e $56 \%$ achavam que o terceirizado realiza mais ações.

Com relação a diferença salarial apenas $35 \%$ disseram que sim, que achavam que o salário era inferior porque "faziam bem mais atividades do que os efetivos", ou que "os efetivos tinham gratificações e eles não", ou que "a data de recebimento dos efetivos era bem mais regular e o salário deles tinha sempre atrasos".

Quando questionados sobre a eficiência, 90\% discordaram que o trabalho do terceirizado era mais eficiente e alegaram que "a falta da certeza de até quando teriam o emprego causava insatisfação", ou "se fossem efetivos poderiam programar o salário e não precisavam fazer outros bicos", e outros disseram que "paravam de viver procurando outro trabalho com medo do desemprego"

Ao término dessa pesquisa, houve um concurso no município para todas as áreas, e na de serviço gerais - a gestora nos informou que passaram 02 (dois) serviços gerais e uma professora para educação infantil.

\section{Considerações Finais}

O presente estudo procurou conhecer as vantagens e desvantagens da terceirização de recursos humanos na saúde e na educação, no campo da administração pública, na visão dos usuários da saúde e de servidores na educação. O empregado terceirizado encontra-se em posição menos favorável relativamente aos trabalhadores envolvidos em relações de emprego típicas; percebe salários menores e não se insere efetivamente na estrutura do empreendimento. Trata-se de uma situação que necessita de "uma forte governança" torná-lo mais igualitário e humanitário.

Se o objetivo final da terceirização é a busca de uma maior eficiência na prestação dos serviços, os resultados encontrados apontaram insatisfação na gestão de alguns serviços. A terceirização de serviços é uma prática importante, mas precisa ainda ser regularizada considerando cada segmento econômico/social. Assim, na visão dos usuários consultados nos segmentos da saúde e da educação, alguns serviços públicos hospitalares ou educacionais não deveriam ser terceirizados, pois são serviços ligados diretamente ao público. No caso dos 
hospitais médicos, enfermeiros, atendentes em geral, assistente social, dentre outros, no sentido de satisfazer melhor o cliente, cada qual em suas necessidades prementes. E nas Escolas, em relação aos que atuam como professores e serviços gerais.

Espera-se que a reforma trabalhista em vista, propicie melhores resultados em relação à privatização dos serviços. Esse tema ainda precisa ser melhor discutido e regulamentado, no momento atual ele está longe de ser concluído.

\section{Referências}

ARTUR, Karen. O TST Frente à Terceirização. 1 ed. São Paulo: Edufscar, 2007.

BARROS, Alice Monteiro. Curso de Direito do Trabalho. 7. Ed. São Paulo: LTr, 2011.

BRASIL. Glossário Jurídico. STF. Repercussão geral.. Disponível em: <http://www.stf.jus.br/portal/glossario/ververbete.asp?letra=r\&id=451>. Acesso em: 05 jan. 2016.

Lei no 6.019, de 3 de janeiro de 1974. Dispõe sobre o Trabalho Temporário nas Empresas Urbanas, e dá outras Providências. Diário Oficial da União, Brasília, DF, 3 jan. 1974. Disponível em: <http://www.planalto.gov.br/ccivil_03/leis/16019.htm>. Acesso em 13 jan. 2016.

Constituição da República Federativa do Brasil de 1988. Disponível:<HTTP://www.planalto.gov.br/ccivil_03/constituicao/constituiçao.htm>. Acesso em 19 de jan de 2016.

Lei $\mathbf{n}^{\circ}$ 5.645, de 10 de dezembro de 1970. Disponível em: <HTTP://www.planalto.gov.br/ccivil_03/leis/L5645.htm>. Acesso em 19 de jan de 2016. CÂMARA DOS DEPUTADOS. Projetos de Leis e Outras Proposições: PL 4330/2004.Disponívelem: $<$ http://www.camara.gov.br/proposicoesWeb/fichadetramitacao?idP roposicao $=267841>$. Acesso em 14 de jan. 2016.

CASSAR, Vólia Bomfim. Direito do Trabalho. 9. ed. Rio de Janeiro: Forense; São Paulo: Método, 2014.

DELGADO, Maurício Godinho. Curso de direito do trabalho. 11. ed. São Paulo: LTr, 2012.

DI PIETRO, Maria Sylvia Zanella. Parceria na Administração Pública. 8 ed. São Paulo: Atlas, 2001. 
GARCIA, Gustavo Filipe Barbosa. Curso de Direito do Trabalho. 8. ed. Rio de Janeiro: Forense, 2014

GIL, Antônio Carlos. Como Elaborar Projetos de Pesquisa. 4. ed. São Paulo: Atlas, 2009.

GIOSA, Lívio A. Terceirização: uma abordagem estratégica. São Paulo: Pioneira, 2008.

LAKATOS, Eva Maria; MARCONI, Marina de Andrade. Metodologia científica. 6 $6^{\text {a }}$ edição.Atlas, 2011. Minha Biblioteca. Disponível em: <http://online.minhabiblioteca.com.br/\#/books/9788522484942/pages/92522116>. Acesso em 16 de jan. 2016.

MIRAGLIA, Lívia Mendes Moreira. A Terceirização Trabalhista no Brasil. 1. ed. São Paulo: Quartier Latin, 2008.

QUEIROZ, Carlos Alberto Ramos Soares de. Manual da terceirização. 3.ed. São Paulo: STS, 2008.

Reforma Trabalhista. Jornal do Commercio.2016,junho,22:160,p.09.

SILVA, Paulo Renato Fernandes. Cooperativas de Trabalho, Terceirização de Serviços e Direito do Trabalho. 2. ed. São Paulo: Ltr, 2013.

Como citar este artigo (Formato ABNT):

SANTOS, O.S.; LOPES JÚNIOR, F.R.; LIMA, A.C.; LIMA, C.C.; LIMA, M.S.M.C. A terceirização dos serviços de administração pública e na educação: um estudo na visão dos usuários desses serviços. Id on Line Revista Multidisciplinar e de Psicologia, Set-Out de 2016, vol.10, n.31, Supl 2, p. 27-41. ISSN 1981-1179.

Recebido: 30/08/2016

Aceito: 08/09/2016 